\title{
Case: Incidental 18F-fluorodeoxyglucose-positron emission tomography/computed tomography prostate uptake: How should these patients be managed?
}

\author{
Anne Couture, BSc, MSc(c); Mounsif Azizi, MD; Daniel Taussky, MD, FRCP(C); \\ Michael McCormack, MD, FRCS(C)
}

Université de Montréal, Centre hospitalier universitaire de Montréal (CHUM), Montreal, QC, Canada

Cite as: Can Urol Assoc J 2017;11 (7):E318-20. http://dx.doi.org/10.5489/cuaj.4426

Published online July 11, 2017

\section{Introduction}

18F-fluorodeoxyglucose-positron emission tomography/ computed tomography (18F-FDG PET/CT) is a widely used diagnostic tool for whole-body imaging, and incidental prostatic uptake occurs in approximately $1 \%$ of patients undergoing the exam. Is 18F-FDG PET/CT a reliable screening tool for prostate cancer? Should these patients undergo transrectal ultrasound (TRUS)-guided prostate biopsies? Studies have indicated that $18 \mathrm{~F}$-FDG PET/CT has a low positive predictive value for prostate cancer and is not recommended for screening; ${ }^{1}$ however, other studies suggest that when a discrete focal 18F-FDG uptake is discovered without coincidental calcification, particularly in the peripheral zone of the prostate, further clinical evaluation is recommended. We present two patients with incidental 18F-FDG PET/CT prostatic uptake who were found to have high-grade prostate cancer. Although 18F-FDG PET/CT has not been determined to be a reliable screening tool for prostate cancer, patients with incidental $18 \mathrm{~F}$-FDG uptake in the prostate should be referred for urological evaluation.

\section{Patient 1}

A 70-year-old man underwent a 18F-FDG PET/CT exam to evaluate a squamous cell carcinoma of the left amygdala. The exam showed a strong incidental bilateral 18F-FDG uptake in the peripheral zone of his prostate. The patient was asymptomatic, but digital rectal exam (DRE) revealed a firm prostate and his serum prostate-specific antigen (PSA) was found to be $47.02 \mathrm{ng} / \mathrm{ml}(0-4.00 \mathrm{ng} / \mathrm{ml})$. TRUS-guided biopsies were done and pathological analysis showed bilateral multiple cores of high-grade prostatic adenocarcinoma with a Gleason score of $9(5+4)$.

\section{Patient 2}

A 77-year-old man was referred for an incidental 18F-FDG uptake in the left peripheral zone of the prostate on a PET/ CT (Fig. 1). No peripheral calcification was seen on the CT scan. The patient was being investigated for colon cancer, which had been operated one year previously. Family history revealed that his father had died from prostate cancer. DRE showed a slightly enlarged benign prostate gland and his serum PSA was measured at $3.3 \mathrm{ng} / \mathrm{ml}$. The patient was highly motivated to undergo a prostate biopsy because of his family history. After informed consent was obtained, TRUSguided prostate biopsies were done and pathological analysis revealed multiple cores of high-grade adenocarcinoma Gleason $9(5+4)$ on the left side of the gland.

\section{Discussion}

18F-FDG PET/CT is a widely used diagnostic tool for wholebody imaging and its use is increasing because it can detect a wide variety of tumour sites. ${ }^{2} 18 \mathrm{~F}-\mathrm{FDG}$ is a glucose analog that reflects local consumption by tissues and shows increased trapping by tumour cells due to increased metabolism. Unfortunately, it has not been very useful in screening for prostate cancer. ${ }^{1,3,4}$ One reason underlying this poor performance is the relatively low metabolic rate of prostate tissue..$^{3-6}$ Also, the proximity of the bladder and the high urinary excretion of 18F-FDG can lead to diagnostic misinterpretations. Moreover, certain benign conditions may be associated with an incidental 18F-FDG uptake, including benign prostatic hyperplasia, bacillus Calmette-Guerin (BCG)-induced granulomatous prostatitis, acute prostatitis, and cystic malformations. ${ }^{1,3,5,7}$ The limited usefulness of $18 \mathrm{~F}-$ FDG in prostate cancer screening has been a motivating factor in developing other radiotracers for prostate cancer. ${ }^{3}$

Nonetheless, the use of 18F-FDG PET/CT is increasing and incidental prostate lesions occur in about $1 \%(0.6-2.3 \%)$ of patients. ${ }^{2,8-13}$ How should these patients be managed? 


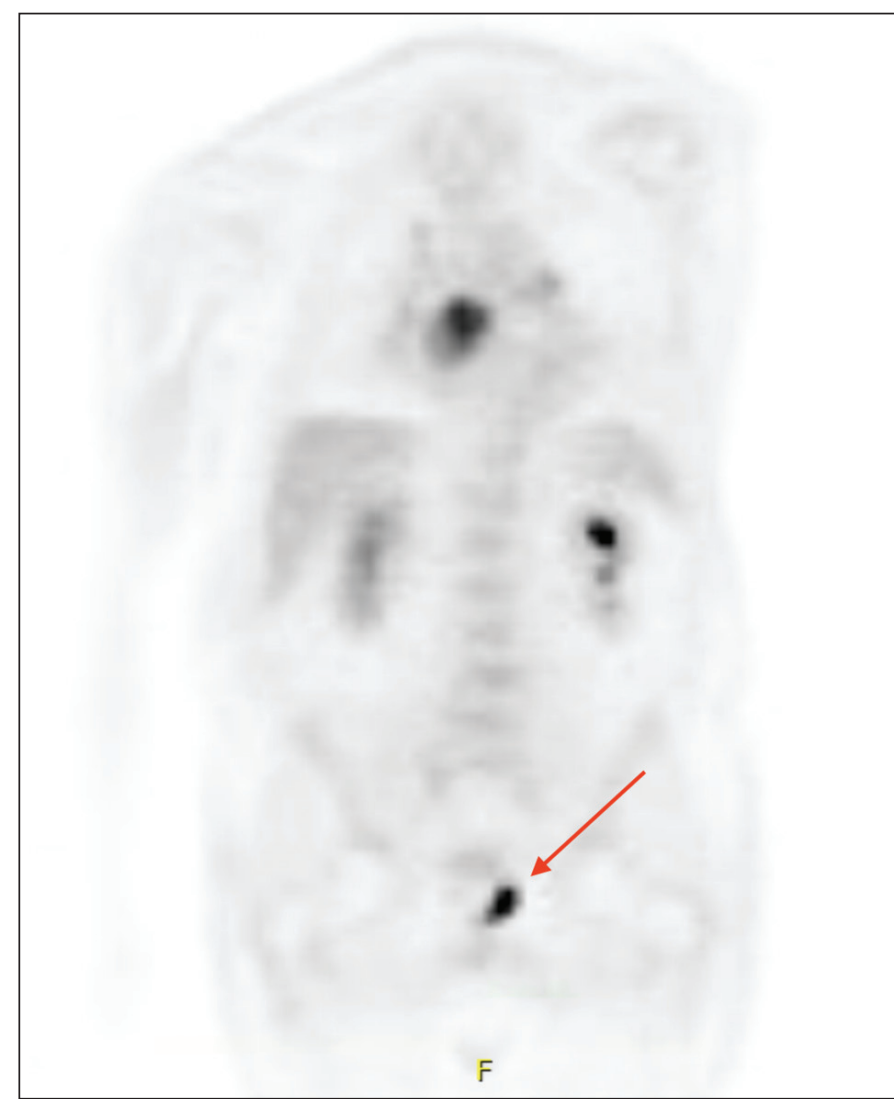

Fig. 1. Incidental $18 \mathrm{~F}$-fluorodeoxyglucose (FDG) uptake in the left peripheral zone of the prostate on positron emission tomography/computed tomography (PET/CT).

Recent literature indicates that patients with incidental 18F-FDG uptake on PET/CT should not be ignored and should have an evaluation including at least DRE and PSA. ${ }^{3} 18$ F-FDG uptake may reflect prostate hypermetabolism and has been associated with high-grade cancer. ${ }^{4,14,15}$ In one study Minamimoto et al concluded that FDG-PET/CT could potentially detect prostate cancer with $80.0 \%$ sensitivity and $87.0 \%$ positive predictive value in cases with a Gleason score of 7 or greater. ${ }^{15}$ Also, the anatomic location of the incidental uptake should be considered. Prostate lesions occurring in the central zone are less likely to be cancerous, whereas peripheral zone uptake is more often associated with cancer. 18F-FDG uptake coexisting with prostate tissue calcification is usually indicative of a benign lesion. ${ }^{6}$

We present two patients with incidental 18F-FDG prostate uptake on PET/CT. Both patients had peripheral zone uptake without concomitant tissue calcifications. Neither of these patients had a history of prostatitis. Interestingly, in both cases, there was a strong correspondence between the 18F-FDG uptake area and the high-grade cancer location within the prostate.

Patient 1 was found to have a firm prostate on DRE and a serum of PSA of $47.02 \mathrm{ng} / \mathrm{ml}$. He underwent TRUS-guided prostate biopsies, which showed bilateral high-grade prostate cancer in the peripheral zone corresponding to the bilateral 18F-FDG uptake area on the PET/CT.

Patient 2 was found to have a slightly enlarged benign prostate gland on DRE and a serum PSA of only $3.3 \mathrm{ng} / \mathrm{ml}$. He was found to have multiple cores of high-grade prostate cancer in the left peripheral zone, which corresponded to the left 18F-FDG uptake area in the prostate.

Studies have indicated that $18 \mathrm{~F}-\mathrm{FDG}$ PET/CT has a low positive predictive value for prostate cancer and is not recommended for screening. ${ }^{1}$ This low positive predictive value might occur because studies have included low-risk prostate cancer (Gleason 6 or less), which have a low metabolism; ${ }^{1}$ however, as is the case for our two patients, incidental 18FFDG uptake may reflect prostate hypermetabolism and can been associated with high-grade cancer. Patients with incidental 18F-FDG PET/CT prostate uptake should be referred to urologists for evaluation.

Competing interests: Dr. Taussky has received research support from Sanofi. The remaining authors report no competing personal or financial interests.

This paper has been peer-reviewed.

\section{References}

1. Reesink DJ, Fransen van de Putte EE, Vegt $E$, et al. Clinical relevance of incidental prostatic lesions on FDG-positron emission tomography/computerized tomography-Should patients receive further evaluation? J Urol 2016;195:907-12. hittps://doi.org/10.1016/i.juro.2015.11.025

2. Yang Z, Hu $S$, Cheng J, et al. Prevalence and risk of cancer of incidental uptake in prostate identified by fluorine-18 fluorodeoxyglucose positron emission tomography/computed tomography. Clin Imaging 2014;38:470-4 https://doi.org/10.1016/i.clinimag.2014.01.019

3. Vali R, Loidl W, Pirich C, et al. Imaging of prostate cancer with PET/CT using 18F-Fluorocholine. Am J Nucl Med Mol Imaging 2015;5:96-108.

4. Jadvar H. PET of glucose metabolism and cellular proliferation in prostate cancer. J Nucl Med 2016;57:25S9S. https://doi.org/10.2967/inumed.115.170704

5. Jadvar H, Ye W, Groshen S, et al. [F-18]-fluorodeoxyglucose PET-CT of the normal prostate gland. Ann Nucl Med 2008;22:787-93. https://doi.org/10.1007/s12149-008-0177-5

6. Kwon T, Jeong IG, You D, et al. Prevalence and clinical significance of incidental 18F-fluoro-2-deoxyglucose uptake in prostate. Korean J Urol 2015;56:288-94. https://doi.org/10.4111/kju.2015.56.4.288

7. Inamura K, Kaii Y, Sakamoto $S$, et al. Abnormal 18F-FDG uptakes in the prostate due to two different conditions of urine reflux: A mimicker of prostate cancer. Springerplus 2016;5:46. https://doi.org/10.1186/s40064-016-1696-5

8. Han EJ, H O J, Choi WH, et al. Significance of incidental focal uptake in prostate on 18-fluoro-2-deoxyglucose positron emission tomography CT images. Br J Radiol 2010;83:915-20. https://doi.org/10.1259/bir/19887771

9. Cho SK, Choi JY, Yoo J, et al. Incidental focal 18F-FDG uptake in the prostate: Clinical significance and differential diagnostic criteria. Nucl Med Mol Imaging 2011;45:192-6. https://doi.org/10.1007/ s13139-011-0092-x

10. Seino $\mathrm{H}, \mathrm{Ono} \mathrm{S}$, Miura $\mathrm{H}$, et al. Incidental prostate 18F-FDG uptake without calcification indicates the possibility of prostate cancer. Oncol Rep 2014;31:1517-22.

11. Kang PM, Seo WI, Lee SS, et al. Incidental abnormal FDG uptake in the prostate on 18-fluoro-2-deoxyglucose positron emission tomography-computed tomography scans. Asian Pac J Cancer Prev 2014;15:8699-703.

12. Bertagna F, Piccardo A, Dib B, et al. Multicentre study of 18F-FDG-PET/CT prostate incidental uptake. Jpn J Radiol 2015;33:538-46. https://doi.org/10.1007/s1 1604-015-0453-y 
Couture et al.

13. Hwang I, Chong A, Jung SI, et al. Is further evaluation needed for incidental focal uptake in the prostate in 18-fluoro-2-deoxyglucose positron emission tomography-computed tomography images? Ann Nucl Med 2013;27:140-5. https://doi.org/10.1007/s12149-012-0663-7

14. Öztürk H, Karapolat I. 18F-fluorodeoxyglucose PET/CT for detection of disease in patients with prostatespecific antigen relapse following radical treatment of a local-stage prostate cancer. Oncology Letters 2016;11:316-22. https://doi.org/10.3892/01.2015.3903
15. Minamimoto R, Uemura H, Sano F, et al. The potential of FDG PET/CT for detecting prostate cancer in patients with an elevated serum PSA level. Ann Nucl Med 2011;25:21-7. https://doi.org/10.1007/ s12149-010-0424-4

Correspondence: Ms. Anne Couture, Université de Montréal, Centre hospitalier universitaire de Montréal (CHUM), Montreal, QC, Canada; anne.couture@umontreal.ca 